\title{
Weapons of Mass Impact: A Growing and Worrisome Danger
}

\author{
Jessica Eve Stern Stanford University, USA
}

$\mathbf{P}$ oison has been used as a weapon throughout history, as well as in literature. Unlike the use of chemical agents by nation-states on the battlefield, terrorists have used poisons with discretion, or in some cases, ineptly. Chemical agents are far more deadly when used against unprotected targets, suggesting that they would have greater utility for terrorists than for battlefield use. But neither criminals nor terrorists have used chemical or biological (C/B) agents to kill large numbers of people. Aum Shinrikyo came close, however, in March 1995, sending over 600 to hospital and killing eleven.

Prior to Aum Shinrikyo, the issue of C/B terrorism garnered little attention, save among a small cadre of specialists with a rather esoteric interest. The cases of $\mathrm{C} / \mathrm{B}$ terrorism that occurred were not known to the general public. And most experts assumed that terrorists would be unlikely to resort to $C / B$ weapons because conventional techniques have worked, and because use of these weapons would carry so many risks: that the opcration will fail due to the inherent unpredictability of the weapon; that the indiscriminate nature of chemical and biological agents makes them unusually dangerous to use (as well as particularly repugnant); or that abhorrence of these weapons would induce a government crack-down or would damage group cohesion.

For somewhat mysterious reasons, $\mathrm{C} / \mathrm{B}$ weapons invoke a horror out of proportion with their lethality. They have been reviled throughout history. Livy called poisoning of enemies "secret crimes." Cicero referred to poisoning as "an atrocity" (Friedman, 1972). And despite the use of chemical weapons $(\mathrm{CW})$ in war, $\mathrm{C} / \mathrm{B} 3$ weapons have been banned repeatedly by international law. I argue that horror of these weapons-their aura of terror-might in fact make $\mathrm{C} / \mathrm{B}$

Jessica Eve Stern, at the time this commentary was written, was a National Fellow at the Hoover Institution at Stanford University. Prior to her position at Hoover, she was Director of Russian, Ukrainian, and Eurasian Affairs at the National Security Council at The White House. Earlier, she was a postdoctoral Arms Control Fellow at I awrence Livermore National Laboratory. Dr. Stern is author of numerous articles on chemical terrorism, control of chemical weapons, and nuclear smuggling from Russia. She is currently writing a book on nuclear, chemical, and biological terrorism. Dr. Stern holds a Ph.l). in public policy from Harvard University. She also holds a B.A. in chemistry and an M.S. in technology policy, and worked previously as a chemist and as an assistant to the U.S. commercial attache in Moscow. E-mail communications should be addressed to J.STERN@ WORLIDNE:I.AT"INEI weapons particularly appealing to certain types of terrorists But terrorists remain unlikely to use biological weapons to conduct acts of "macro-terrorism," involving as many hundreds of thousands of deaths.

Tucker provides a brilliant analysis of the most recent, and most dramatic case of CW terrorism, Aum Shinrikyo's use of sarin on the Tokyo subway in March 1995. He also provides an excellent analysis of the technical hurdles terrorists would face in resorting to these weapons, as well as useful policy recommendations. This commentary is less a critique than a supplementary discussion of whether terrorists are likely to use these weapons again, the kinds of tactics they might employ, and the types of terrorists most prone to resort to them.

I concur with Tucker that constraints against $\mathrm{C} / \mathrm{B}$ terrorism continue to erode, and that the prospect for $\mathrm{C} / \mathrm{B}$ terrorism is rising. I would argue, in contrast with Tucker, that because these weapons are inherently terrorizing, they are even better suited for attracting attention than for creating mass casualties. Aum Shinrikyo's actions significantly eroded a psychological taboo against $\mathrm{C} / \mathrm{B}$ weapons, but did not break the taboo against conducting truly mass destruction. The implication of this assessment is that governments should be prepared for low-technology operations, including contamination of consumables and closed-area air dissemination, operations that employ these agents as weapons of mass impact rather than weapons of mass destruction.

Brian Jenkins's oft repeated observation, "terrorists want a lot of people watching, not a lot of people dead," has been interpreted to imply that terrorists would not resort to weapons of mass destruction, including $\mathrm{CBW}$. Tucker argues that terrorist groups might be drawn to $\mathrm{C} / \mathrm{B}$ weapons if they "are intent on inflicting mass casualties rather than attracting attention to their political cause." While Aum was fairly unusual among known terrorist groups in "wanting a lot of people dead," and in electing to use CW to meet that objective, other terrorists might be attracted to weapons of mass impact for precisely the opposite reason-to attract attention to their cause without inflicting mass casualties. Chemical and biological weapons (and even radiological and nuclear weapons, for that matter) don't have to be used as weapons of mass destruction. Even when used on a relatively small scale, these weapons could nonetheless attract much more attention than conventional weapons, and could do a great deal of damage to the citizens' faith in the target government. 
Consider the likely reaction if the Oklahoma bombing had resulted in 168 ebola or plague deaths, rather than the conventional bombing that actually occurred. The Aum intended to kill many thousands of people, but because the Tokyo incident was conducted in haste using a crude delivery device, eleven people died. Ordinarily, Americans pay scant attention to events involving foreigners overseas. But Aum has persisted in the public eye-partly because the Tokyo incident occurred nearly contemporaneously with the April 1995 Oklahoma bombing, but also because the group employed a still novel technique-chemical weapons. (Were terrorists to choose a contagious biological agent, they might have trouble controlling the results of the attack-even if their intent was to limit casualties. In part for this reason, contagious agents are probably less attractive than chemical agents or anthrax.)

The Aum case raises several important questions: Could it happen again? What kinds of terrorists would be most prone to use chemical or biological weapons? Might the next incident involve the use of $\mathrm{CBW}$ as a mass-destruction weapon, killing hundreds, or even thousands?

There are few data to help answer these questions. First, terrorists have rarely used these weapons in the past. Second, Rand has ceased maintaining its CBW terrorism database of contamination incidents (Rand). Third, while the U.S. State Department maintains a fairly comprehensive database on international terrorism incidents (incidents perpetrated by groups based outside the target country), there are no aggregate data on worldwide domestic incidents (incidents perpetrated by groups based inside the target country, such as violence perpetrated by the Shining Path in Peru), and only a few countries maintain such databases even for internal use. In the absence of reliable data the analyst is forced to rely on hypothesis, deduction, and speculation, which has led to a rather sloppy debate.

These questions are considered below from three perspectives: (1) by analyzing constraints against CBW use and considering which terrorists appear most likely to be able to overcome them; (2) by analyzing the types of terrorists that have produced, threatened to use, or actually used CBW in the past, and by a process of induction developing a list of possible red flags and likely tactics; and (3) by analyzing broad trends in terrorist activities.

\section{Constraints}

Two broad types of constraints appear to have impeded terrorists in the past: technical difficulties and political or moral constraints. Technical constraints are clearly eroding. A study conducted by the U.S. Congress Office of Technology Assessment in 1991 concluded that for some scenarios involving $\mathrm{CBW}$, "the level of technological sophistication required... may be lower than was the case for some of the sophisticated bombs that have been used against civilian aircraft" (Office of Technology Assessment, 1991:51-52).
A 1984 National Intelligence Estimate reportedly concluded that clandestine production of crude chemical and biological weapons requires no greater technical expertise than does production of narcotics or heroin (Anderson, 1984). While sophisticated delivery systems for chemical and especially biological agents are likely to be out of reach of most terrorists, especially those lacking state sponsors, low-technology delivery systems that could be used to kill hundreds are within reach of groups capable of recruiting universitytrained chemists or biologists. By low-technology delivery systems, I mean poisoning food or water, dumping a chemical agent into the air intake duct of a building, or releasing a volatile chemical agent (such as sarin) into an enclosed space such as a train or plane.

Higher technology delivery systems out of reach of most terrorists include air dissemination over large areas. Drying and milling biological agents to a powder with particles of appropriate diameter (1-7 microns) is extremely difficult and would - according to one authority - be out of reach of many countries, let alone terrorists (Lowe, 1996). Terrorists' capacity to disseminate $\mathrm{C} / \mathrm{B}$ weapons over large areas is the subject of much debate, however (Purver, 1995).

From a technical point of view, any terrorist group known to recruit well-trained chemists and biologists should be on analysts' radar screens for possible use of lower technology $\mathrm{C} / \mathrm{B}$ operations. Red flags for possible use of more sophisticated CBW are a group's ability to generate large amounts of capital (enabling it to buy weapons or expertise); recruitment of well-trained scientists; or state sponsorship. Statesponsored terrorists may be capable of using sophisticated devices, since most state sponsors of terrorism also have CBW programs. Iran, Iraq, Libya, North Korea, and Syria-all listed by the State Department as state sponsors of terrorism-are suspected or known to harbor CBW programs. But state-sponsored groups may face extra political constraints, as explained below.

In contrast to technical difficulties, political or moral concerns are likely to be binding for most terrorists. Terrorists have been technically capable of killing many more people than they actually have-even by using traditional methods. Impediments to more lethal acts include terrorists' fear that going too far could risk betrayal of the operation, and fear of a public backlash or an unprecedented government crackdown (Jenkins, 1996). Many terrorists see themselves as the vanguard of a political movement whose constituency is supportive, but finicky and squeamish. The IRA, for example, would probably be much less effective in fund-raising operations on the Boston Common were the group to employ bubonic plague as a weapon. And some terrorists, Jenkins argues, would find using weapons of mass destruction morally repugnant.

While state-sponsored terrorists are clearly the most likely to be able to overcome technical obstacles, they may face an additional political constraint. The sponsoring state may fear that despite its best efforts to hide its hand, the target government will discover its involvement and 
retaliate, particularly if weapons of mass destruction are used. On the other hand, a number of particularly violent state-sponsored incidents in recent years make clear that it would be imprudent to rely on traditional deterrence against state-sponsored terrorists, even when it comes to use of weapons of mass destruction.

Terrorists likely to feel unconstrained by the above-listed moral or political concerns include groups that (a) perceive an amorphous constituency; (b) do not depend on their target audience for raising capital; (c) are motivated by such strong racial or ethnic hatred that killing carries no moral burden; (d) are motivated by a religious extremism that makes them reject conventional morality, or provides them with a direct line of communication to a god that encourages extreme violence; (e) reject society as so corrupt or polluting that traditional mores must be rejected in the fight to turn society around; and (f) feel isolated or superior to society, and not subject to its norms.

\section{Types of Terrorists}

It is also useful to consider the types of terrorists that have used, or planned to use, CBW, and induce from their characteristics possible warning signs. As Tucker and others have pointed out, the case of Aum Shinrikyo suggests that we should be concerned about groups with apocalyptic or millennialist views. The final years of centuries have often been met with acts of extreme violence, and the end of the millennium may provoke even more extreme outbursts. Such groups are likely to meet at least five of the conditions outlined in the paragraph above.

Tucker also refers to four cases in which right-wing extremists have acquired biological agents-the Minnesota Patriots Council's plan to use ricin to assassinate IRS agents; a neo-Nazi white supremacist's purchase of bubonic plague; and a survivalist's attempt to smuggle a large quantity of ricin from Canada to the United States. Earlier, in 1972, another U.S. group of neo-Nazis, the Order of the Rising Sun, was found in possession of a large quantity of typhoid bacillus that they had apparently produced themselves. The group reportedly intended to use the agent to poison water supplies in several Midwestern cities. Experts argue that violent right-wing extremists often despise the masses, favoring imposition of order at any cost, and they are often racial supremacists-making them possible candidates for WMD terrorism on two counts.

Eco-terrorists have been involved in a number of tampering incidents (Purver, 1995). So far, they have specialized in poisoning foods. While many eco-terrorists might be reluctant to employ $\mathrm{C} / \mathrm{B}$ weapons on a large scale, given the likely adverse effect on the environment, terrorists often rationalize operations that employ tactics inconsistent with their political views in the apparent belief that the end justifies the means. The Unabomber, who occasionally used sophisticated explosives, appears not to have been troubled by the high-technology nature of his weapons, despite his Luddite views. To the list of six broad characteristics of groups more likely to resort to weapons of mass destruction, we might therefore add, based on past occurrences, three more specific characteristics: millennialist or apocalyptic groups; violent right-wing extremists; and eco-terrorists (at least for product-tampering cases).

\section{Trends in Terrorist Activities}

Of 195 incidents that I analyzed in 1992 from an extract of the Rand Database of Contamination Incidents, 20 resulted in at least one death, 80 had the potential to cause fatalities, and 24 resulted in at least one injury. The total number of deaths was 86 , and the total number of injuries was uncertain (Stern, 1993). Food was the preferred target of contamination for both terrorists and criminals, comprising $45 \%$ of the incidents. Food is also the most common of tampering complaints received by the FDA. Water contamination comprised $19 \%$ of the incidents, and pharmaceuticals $10 \%$. Air dissemination, the most difficult $\mathrm{CBW}$ operation, was attempted or threatened in only $10 \%$ of the incidents. Assault on persons constituted $10 \%$ of the incidents, followed by sabotage, comprising $9 \%$.

Slightly less than half of the incidents-41\%-involved threats that were never carried out. Unfulfilled threats are by no means harmless, however. They may cost a great deal in terms of consumers' confidence in the safety of products or foods (which is ultimately translated into lost revenues), and can damage citizens' confidence in their government.

\section{Conclusion}

Thus far, terrorists have used $\mathrm{C} / \mathrm{B}$ weapons as weapons of mass impact rather than as weapons of mass destruction. Broad trends in terrorist activities are worrisome from the point of view of predicting the likelihood of more violent C/B terrorism, however. Terrorists are increasingly targeting random, innocent bystanders; weapons and tactics are increasingly sophisticated; chemical and biological weapons are proliferating to terrorist-supporting states; and the taboo against $\mathrm{C} / \mathrm{B}$ weapons continues to erode. Nonetheless, "macro-terrorism," resulting in hundreds of thousands of deaths, remains unlikely.

Protecting the population from terrorism entails tradeoffs from the point of view of civil liberties. Instructions for conducting acts of $\mathrm{C} / \mathrm{B}$ terrorism, available on the Internet as well as in widely advertised manuals, are protected under the First Amendment. The use of the armed forces to protect Americans at home is limited by the posse comitatus statute. And electronic communication is protected by the Fourth Amendment. Given the possible cost of nonaction, however, these-and other policy prescriptions recommended by Tucker-are worth careful consideration. 


\section{References}

Anderson, J. (1984). "Chemical Arms in Terrorism Feared by the CIA." The Washington Post (August 27).

Friedman, L., ed. (1972). The Law of War: A Documentary History. New York: Random House.

Jenkins, B. (1996). Kroll Associates. Remarks at conference "ChemBio Terrorism: Wave of the Future?" Park Hyatt Hotel, Washington DC, April 29.

Lowe, K. (1996). Institute for Defense Analysis. Remarks at conference "ChemBio Terrorism: Wave of the Future?" Park Hyatt
Hotel, Washington DC, April 29.

Office of Technology Assessment (1991). Technology Against Terrorism: The Federal Effort. Washington, DC: U.S. Government Printing Office.

Purver, R. (1995). "Chemical and Biological Terrorism: The Threat According to the Open Literature." Canadian Security Intelligence Service, June.

Rand. Rand Database of Contamination Incidents. See Stern (1993) for limitations of database.

Stern, J. (1993). "Will Terrorists Turn to Poison?" Orbis 37 (Summer):393-410.

\title{
Fighting CBW Terrorism: Means and Possibilities
}

\author{
Thomas Stock Stockholm International Peace Research Institute, Sweden
}

I n his article "Chemical/Biological Terrorism: Coping with a New Threat," Jonathan Tucker argues that, based on the experience of the March 1995 release of nerve agent on the Tokyo subway by terrorists, there is a need to evaluate existing counterterrorism strategies, in general, and those for chemical and biological terrorism, in particular. Any such strategy should be based on preemption and civil defense. Tucker discusses several short-term and long-term policy options for meeting this new threat and focuses primarily on the United States.

\section{Terrorism and New Technology}

There is no doubt that the technological developments of the past filty ycars have added to the arsenal of weapons available to terrorists. Thus far, however, terrorists have not been particularly innovative and have limited their activities to bombing, shooting, hostage-taking, kidnapping, and skyjacking.

Thomas Stock (Germany) is Leader of the SIPRI Chemical and Biological Warfare Project and Series Editor of the SIPRI Chemical and Biological Warfare Studies. He is an analytical chemist, with research experience in analytical chemistry and chemical toxicology. He is coeditor of National Implenientation of the Funure Chemical Weapons Convention (1990), Verification after the Cold War: Broadening the Process (1994), and The Challenge of Old Chenical M.funitions and Toxic Ammament Wastes (forthcoming, 1996). Dr. Stock has contributed to the SIPRI Yearbook since 1991, and has written extensively on the verification and national implementation of chemical disarmament accords and on old and abandoned chemical weapons. Correspondence should be sent to SIPRI, Frösunda, S-171 53 Solna, Sweden (E-mail: STOCK(aSIPRI.SE).
Why are chemical weapons (CW) potentially attractive to terrorists and how might they be perceived as preferable to nuclear weapons for terrorist use? Chemical weapons are widely considered as easier to manufacture or obtain, less likely to be detected, and more reliable to use (they can be tested) than nuclear weapons. There are certain putative advantages of chemical and biological agents for terrorists:

- the horrible nature of their effects-heightening terror and tending to cause panic;

- their indetectability by traditional antiterrorist sensor systems;

- the difficulty of defending against chemical and biological agents;

- compared to conventional arms, the ease with which they can be disguised, transported, and introduced into a target area;

- the possibility for individual assassination or low-level attacks;

- the possible time lag between release of the agent and its perceived effects on humans;

- the lack of signature-possibility for anonymous attacks;

- some agents are temporarily incapacitating, rather than lethal;

- the technical equipment for preparation on a small scale is easily purchased;

- the technologies to produce chemical agents are well described in the open literature;

- the processes involved in preparation of toxic agents are standard ones of practicing organic chemists; and

- although the delivery of toxic agents involves a certain risk to the deliverer, there are various pathways that are highly effective (e.g., municipal water and air supply systems). ${ }^{1}$ 